\title{
Computational Search for Novel Hard Chromium-Based Materials
}

\author{
Alexander G. Kvashnin, ${ }^{1,2, *}$ Artem R. Oganov, ${ }^{1,2,3,4}$ Artem I. Samtsevich, ${ }^{1}$ Zahed Allahyari ${ }^{1,2}$ \\ ${ }^{1}$ Skolkovo Institute of Science and Technology, Skolkovo Innovation Center 143026, 3 \\ Nobel Street, Moscow, Russian Federation \\ ${ }^{2}$ Moscow Institute of Physics and Technology, 141700, 9 Institutsky lane, Dolgoprudny, \\ Russian Federation \\ ${ }^{3}$ Department of Geosciences and Center for Materials by Design, Institute for Advanced \\ Computational Science, State University of New York, Stony Brook, NY 11794-2100 \\ ${ }^{4}$ International Center for Materials Design, Northwestern Polytechnical University, Xi'an, \\ 710072, China
}

\begin{abstract}
.
Nitrides, carbides and borides of transition metals are an attractive class of hard materials. Our recent preliminary explorations of the binary chemical compounds indicated that chromiumbased materials are among the hardest transition metal compounds. Motivated by this, here we explore in detail the binary $\mathrm{Cr}-\mathrm{B}, \mathrm{Cr}-\mathrm{C}$ and $\mathrm{Cr}-\mathrm{N}$ systems using global optimization techniques. Calculated enthalpy of formation and hardness of predicted materials were used for Pareto optimization to define the hardest materials with lowest energy. Our calculations recover all numerous known stable compounds (except $\mathrm{Cr}_{23} \mathrm{C}_{6}$ with its large unit cell) and discover a novel stable phase $P m n{ }_{1}{ }_{1}-\mathrm{Cr}_{2} \mathrm{C}$. We resolve the structure of $\mathrm{Cr}_{2} \mathrm{~N}$ and find it to be of anti- $\mathrm{CaCl}_{2}$ type (space group Pnnm). Many of these phases possess remarkable hardness, but only $\mathrm{CrB}_{4}$ is superhard (Vickers hardness $48 \mathrm{GPa}$ ). Among chromium compounds, borides generally possess highest hardnesses and greatest stability. Under pressure, we predict stabilization of a TMDClike phase of $\mathrm{Cr}_{2} \mathrm{~N}$, a WC-type phase of $\mathrm{CrN}$, and a new compound $\mathrm{CrN}_{4}$. Nitrogen-rich chromium nitride $\mathrm{CrN}_{4}$ is a high energy-density material featuring polymeric nitrogen chains. In the presence of metal atoms (e.g. Cr) polymerization of nitrogen takes place at much lower pressures: $\mathrm{CrN}_{4}$ becomes stable at $\sim 15 \mathrm{GPa}$ (cf. $110 \mathrm{GPa}$ for synthesis of pure polymeric nitrogen).
\end{abstract}

\section{Introduction}

Generally, the hardest and most popular superhard materials known to date belong to two groups - (1) some B-C-N compounds and their derivatives (e.g., Refs. ${ }^{1,2}$ ), and (2) nitrides, carbides and borides of some transition metals. Compounds of the first class are semiconducting and brittle and the best known superhard phases (i.e. with Vickers hardness $>40 \mathrm{GPa}$ ) belong to it, whereas those of the second class are metallic and more ductile. These two classes of very hard materials were uncovered in our preliminary computational searches. We explore a number of combinations with these elements, searching for materials with the best property (e.g. highest hardness, computed using the Lyakhov-Oganov model ${ }^{3}$ ). We indeed found 
diamond to be the hardest possible single crystal material, B-C-N phases to have the highest hardnesses, and among non-B-C-N compounds the $\mathrm{Cr}-\mathrm{B}, \mathrm{Cr}-\mathrm{C}$ and $\mathrm{Cr}-\mathrm{N}$ systems were indicated among the most promising for the existence of new hard and superhard materials. Indeed, recent theoretical studies of chromium nitrides and borides reported that $\mathrm{CrB}_{4}$ and hypothetical metastable $\mathrm{CrN}_{2}$ and can have hardness of $47 \mathrm{GPa},{ }^{4,5}$ and $46 \mathrm{GPa},{ }^{6}$ respectively.

Usually, chromium metal and its compounds are used in a wide range of applications mainly related to wear-resistant coatings, ${ }^{7-12}$ cutting tools ${ }^{13,14}$ and metal forming and plastic moulding applications. ${ }^{15}$ Chromium nitride, $\mathrm{CrN}$, is often used on medical implants and tools as a coating material due to its good wear, oxidation and corrosion resistance. ${ }^{9-11} \mathrm{CrN}$ is also a valuable component in advanced multicomponent coating systems, such as CrAlN, for hard, wearresistant applications on cutting tools. ${ }^{16}$

Experimentally, six different chromium borides $\left(\mathrm{Cr}_{2} \mathrm{~B}, \mathrm{Cr}_{5} \mathrm{~B}_{3}, \mathrm{CrB}, \mathrm{Cr}_{3} \mathrm{~B}_{4}, \mathrm{CrB}_{2}\right.$ and $\left.\mathrm{CrB}_{4}\right)$ are known, ${ }^{17-21,4}$ and recently their mechanical characteristics were examined theoretically. ${ }^{4,5,22}$ The experimental Vickers hardness of most $\mathrm{Cr}$-B phases ranges from 20.7 to $24 \mathrm{GPa},{ }^{23,24}$ while Vickers hardness of $\mathrm{CrB}_{4}$ phase was reported to be in a range of 29-44 $\mathrm{GPa}$. ${ }^{24}$

It is known from experiments, that there are three stable chromium carbides, $\mathrm{Cr}_{23} \mathrm{C}_{6}, \mathrm{Cr}_{3} \mathrm{C}_{2}$ and $\mathrm{Cr}_{7} \mathrm{C}_{3} \cdot{ }^{12-14,25,26}$ Powders of $\mathrm{Cr}_{3} \mathrm{C}_{2}$ were prepared by heat-treatment of metastable chromium oxides of controlled morphology in $\mathrm{H}_{2}-\mathrm{CH}_{4}$ atmosphere. ${ }^{8}$ Other metastable chromium carbides such as $\mathrm{CrC}$ and $\mathrm{Cr}_{3} \mathrm{C}$ have also been synthesized. ${ }^{27-30}$ Theoretically calculated values of Vickers hardness of chromium carbide phases by Šimůnek model ${ }^{31}$ vary from 13 to $32 \mathrm{GPa},{ }^{32}$ which is in a good agreement with experiments. ${ }^{33-35}$

Chromium nitrides are less studied, with most experimental works devoted to $\mathrm{CrN}$ and reporting the existence of a cubic paramagnetic B1-phase (NaCl-type) with $F m \overline{3} m$ space group. ${ }^{36,37}$ However, at temperatures below the Néel temperature $(200-287 \mathrm{~K}){ }^{37-40} \mathrm{~B} 1-\mathrm{CrN}$ phase transforms to an orthorhombic antiferromagnetic phase with Pnma space group ${ }^{37,39}$ and this transition was studied theoretically. ${ }^{41}$ Today, electronic and magnetic properties of chromium nitride at low temperatures are actively studied. ${ }^{37,41-44}$

In addition to $\mathrm{CrN}$, there is another stable compound $\mathrm{Cr}_{2} \mathrm{~N}$, which appears together with $\mathrm{CrN}$ during the fabrication of $\mathrm{Cr}-\mathrm{N}$ films and displays comparable wear resistance, but worse oxidation resistance. ${ }^{45-48}$ Coating of $\mathrm{Cr}_{2} \mathrm{~N}$ can be synthesized by either solid-state metathesis reaction of $\mathrm{CrCl}_{3}$ with $\mathrm{Li}_{3} \mathrm{~N}{ }^{49}$ or by controlling the $\mathrm{N}$ flux. ${ }^{47,48,50-52}$ Theoretically predicted crystal structure of $\mathrm{Cr}_{2} \mathrm{~N}^{53}$ was based on experimental data made by Eriksson, ${ }^{50}$ which reported about hexagonal close-packed structure with $P \overline{3} 1 \mathrm{~m}$ space group with lattice parameters $a=4.752 \AA, c=4.429 \AA$. Recently, comprehensive first-principles calculations of atomic structure and physical properties of different $\mathrm{Cr}_{2} \mathrm{~N}$ phases with only varying distribution of the $\mathrm{N}$ atoms. ${ }^{54}$

It is important that none of the above mentioned works attempted global optimization of Cr$\mathrm{B}, \mathrm{Cr}-\mathrm{C}$ and $\mathrm{Cr}-\mathrm{N}$ systems and considered only already known or hypothesized compounds.

In this paper we explore the $\mathrm{Cr}-\mathrm{B}, \mathrm{Cr}-\mathrm{C}$ and $\mathrm{Cr}-\mathrm{N}$ systems using evolutionary structure prediction algorithm USPEX and density functional theory. The structure, stability, elastic constants and hardness of all considered phases are studied in detail.

\section{Results and Discussions}

First, we searched for stable compounds in the $\mathrm{Cr}-\mathrm{B}, \mathrm{Cr}-\mathrm{C}$ and $\mathrm{Cr}-\mathrm{N}$ systems at zero pressure. Based on the calculated enthalpies of formation of predicted phases for different compositions, convex hull diagrams were constructed, shown in Fig. 2a-c. Red points in the convex hull 
diagrams correspond to thermodynamically stable phases (see Fig. 2a-c), green points are studied metastable phases (see Fig. 2c,f). One can note from Fig. 2a, that five chromium borides were found including $I 4 / m-\mathrm{Cr}_{2} \mathrm{~B}, I 4 / m c m-\mathrm{Cr}_{5} \mathrm{~B}_{3}, C m c m-\mathrm{CrB}, I m m m-\mathrm{Cr}_{3} \mathrm{~B}_{4} P 6 / m m m-\mathrm{CrB}_{2}$ and $\mathrm{Pnnm}-\mathrm{CrB}_{4}$. All these predicted phases were already known from previous experimental works, ${ }^{18,19,24}$ and are successfully found here in an unbiased calculation.

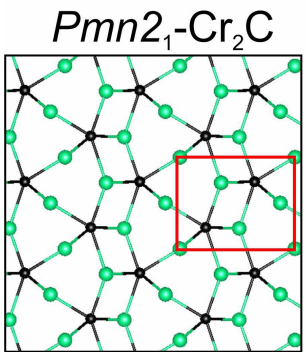

Immm- $\mathrm{Cr}_{3} \mathrm{~B}_{4}$

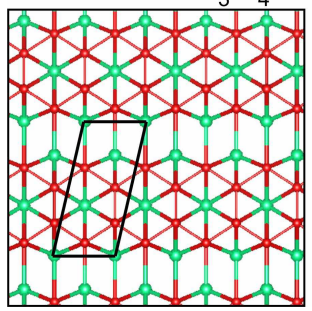

$P$ nna- $\mathrm{Cr}_{3} \mathrm{C}_{2}$

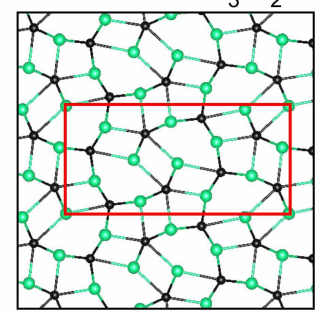

$14 / \mathrm{mcm}^{-\mathrm{Cr}_{5} \mathrm{~B}_{3}}$

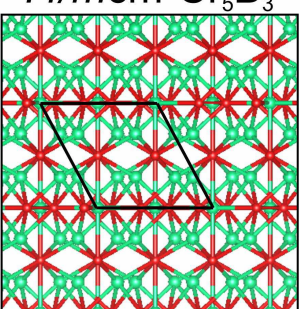

Pnma- $\mathrm{Cr}_{7} \mathrm{C}_{3}$

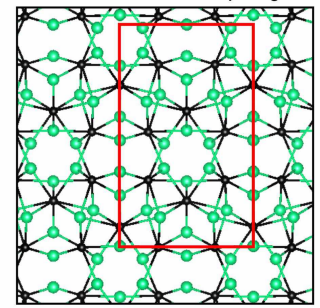

Cmcm-CrB

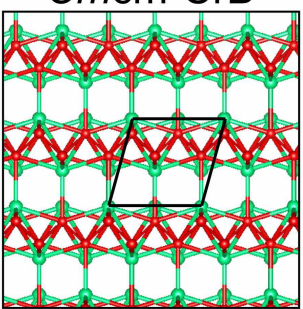

$F m \overline{3} m-\mathrm{Cr}_{23} \mathrm{C}_{6}$

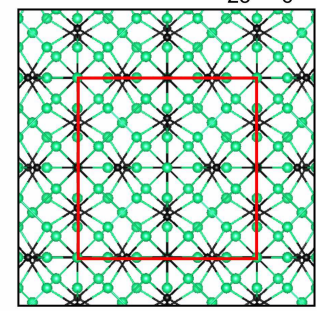

$P 6 / \mathrm{mmm}^{-\mathrm{CrB}}$

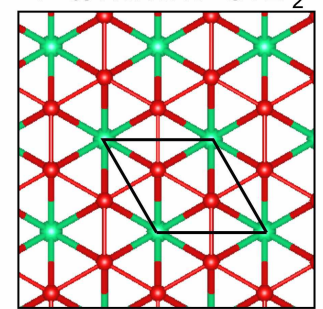

$14 / m-\mathrm{Cr}_{2} \mathrm{~B}$

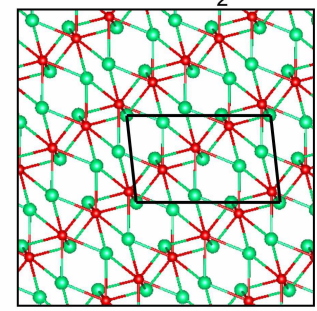

Pnnm-CrB

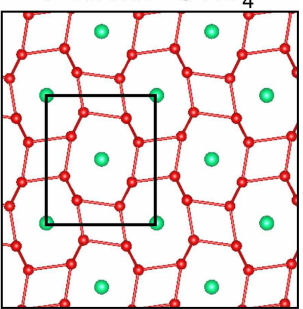

Fig. 1 Crystal structures of predicted $\mathrm{Cr}-\mathrm{C}$ and $\mathrm{Cr}-\mathrm{B}$ phases. $\mathrm{Cr}$ atoms are green, carbon is black, and boron is red.

During the evolutionary search of the $\mathrm{Cr}-\mathrm{C}$ system, we found only three thermodynamically stable phases of chromium carbides shown in Fig. 2 b by red points: $P n m a-C_{7} C_{3}, P m n 2_{1}-C_{2} C_{\text {, }}$ Pnma- $\mathrm{Cr}_{3} \mathrm{C}_{2}$. However, there is one stable phase $\mathrm{Cr}_{23} \mathrm{C}_{6}$ with $F m \overline{3} m$ space group, which has not been found due to a large number of atoms (29) in the unit cell (blue point in Fig. 2b). The crystal structure of $F m \overline{3} m-\mathrm{Cr}_{23} \mathrm{C}_{6}$ was taken from experiment ${ }^{32}$ and the formation enthalpy was calculated to compare it with found structures. All found phases except $P m n 2-\mathrm{Cr}_{2} \mathrm{C}$ were synthesized experimentally. ${ }^{8,25}$ In the $\mathrm{Cr}-\mathrm{N}$ system, only two thermodynamically stable phases were found: Pnma-CrN and $P n n m-\mathrm{Cr}_{2} \mathrm{~N}$. These phases were experimentally synthesized in a number of studies, ${ }^{36,37,47-52}$ although the structure of $\mathrm{Cr}_{2} \mathrm{~N}$ remained unknown. Other predicted phases, denoted by green points, are metastable (see Fig. 2 c). Structural parameters of all predicted phases are summarized in Table 1, and illustrated in Fig. 1.

Table 1. Details of atomic structure of predicted $\mathrm{Cr}-\mathrm{B}$ and $\mathrm{Cr}-\mathrm{C}$ phases.

\begin{tabular}{|c|c|c|c|c|}
\hline Comp. & Space group & $\begin{array}{c}\text { Lattice } \\
\text { parameters, } \AA\end{array}$ & $\begin{array}{c}\mathrm{V}, \\
\AA^{3} / \text { unit }\end{array}$ & $\begin{array}{c}\rho, \\
\mathrm{g} / \mathrm{cm}^{3}\end{array}$ \\
\hline $\mathrm{Cr}_{2} \mathrm{~B}$ & $I 4 / m$ & $\mathrm{a}=4.21, \mathrm{~b}=6.59, \mathrm{c}=4.04$ & 27.95 & 6.82 \\
\hline $\mathrm{Cr}_{5} \mathrm{~B}_{3}$ & $\mathrm{I} / \mathrm{mcm}$ & $\mathrm{a}=5.43, \mathrm{~b}=2.66, \mathrm{c}=4.56$ & 73.15 & 6.64 \\
\hline $\mathrm{CrB}$ & $\mathrm{Cmcm}$ & $\begin{array}{c}\mathrm{a}=2.92, \mathrm{~b}=7.84, \mathrm{c}=2.92 \\
(\text { theor: } \mathrm{a}=2.93, \mathrm{~b}=7.84, \mathrm{c}=2.92)^{21} \\
(\exp : \mathrm{a}=2.959, \mathrm{~b}=7.846, \mathrm{c}=2.919)^{21}\end{array}$ & 66.79 & 6.25 \\
\hline $\mathrm{Cr}_{3} \mathrm{~B}_{4}$ & Immm & $\mathrm{a}=\mathrm{b}=2.92, \mathrm{c}=6.54$ & 55.82 & 5.93 \\
\hline $\mathrm{CrB}_{4}$ & Pnnm & $\begin{array}{c}\mathrm{a}=5.47, \mathrm{~b}=2.85, \mathrm{c}=4.72 \\
(\exp : \mathrm{a}=5.48, \mathrm{~b}=2.87, \mathrm{c}=4.74)^{4,24} \\
(\exp : \mathrm{a}=5.48, \mathrm{~b}=2.87, \mathrm{c}=4.75)^{20}\end{array}$ & 36.85 & 4.29 \\
\hline
\end{tabular}




\begin{tabular}{|c|c|c|c|c|}
\hline $\mathrm{CrB}_{2}$ & $P 6 / \mathrm{mmm}$ & $\begin{array}{l}\quad \mathrm{a}=\mathrm{b}=2.98, \mathrm{c}=2.91 \\
\text { (theor: } \mathrm{a}=\mathrm{b}=2.97, \mathrm{c}=3.08)^{55} \\
(\exp : \mathrm{a}=\mathrm{b}=2.97, \mathrm{c}=3.07)^{17,24}\end{array}$ & 22.46 & 5.44 \\
\hline $\mathrm{Cr}_{7} \mathrm{C}_{3}$ & Pnma & $\begin{array}{c}\mathrm{a}=4.48, \mathrm{~b}=6.94, \mathrm{c}=12.01 \\
(\text { theor: } \mathrm{a}=4.51, \mathrm{~b}=6.91, \mathrm{c}=12.08)^{32} \\
(\exp : \mathrm{a}=4.53, \mathrm{~b}=7.01, \mathrm{c}=12.14)^{56}\end{array}$ & 93.46 & 7.11 \\
\hline $\mathrm{Cr}_{2} \mathrm{C}$ & $\operatorname{Pmn} 2_{1}$ & $\mathrm{a}=5.01, \mathrm{~b}=2.82, \mathrm{c}=3.98$ & 28.13 & 6.85 \\
\hline $\mathrm{Cr}_{3} \mathrm{C}_{2}$ & Pnma & $\begin{array}{c}\mathrm{a}=2.78, \mathrm{~b}=5.47, \mathrm{c}=11.45 \\
(\text { theor: } \mathrm{a}=2.79, \mathrm{~b}=5.48, \mathrm{c}=11.47)^{32} \\
(\exp : \mathrm{a}=2.83, \mathrm{~b}=5.55, \mathrm{c}=11.49)^{57}\end{array}$ & 43.72 & 6.84 \\
\hline $\mathrm{Cr}_{23} \mathrm{C}_{6}$ & $F m \overline{3} m$ & $\begin{array}{c}\mathrm{a}=\mathrm{b}=\mathrm{c}=10.82 \\
(\text { theor: } \mathrm{a}=\mathrm{b}=\mathrm{c}=10.56)^{32} \\
(\exp : \mathrm{a}=\mathrm{b}=\mathrm{c}=10.66)^{58}\end{array}$ & 291.04 & 7.09 \\
\hline
\end{tabular}

Let us now consider results of Pareto optimization shown in Fig. 2d-f. All points, which belong to a certain Pareto front, are connected by black line. The first Pareto front contains phases with simultaneously optimal high hardness (estimated using Lyakhov-Oganov model ${ }^{3}$ ) and maximum stability (measured as vertical distance from the convex hull). We consider the most promising phases, which are located mostly in the first five Pareto fronts, shown by red and open circles, which lie on the convex hull or close to it (see Fig. 2d-f). We note that the Lyakhov-Oganov model, convenient, numerically stable, and usually reliable, was used for Pareto-screening (and shown in Fig. 2) - however, it must be noted that Chen's model ${ }^{59}$ is more accurate (these values are given in Table 2 and taken as final theoretical hardnesses in this work).

The most remarkable hardnesses, as well as largest negative enthalpies of formation, are seen in the $\mathrm{Cr}$-B system. $\mathrm{CrB}_{4}$ is predicted to be superhard $\left(H_{v}=47.6 \mathrm{GPa}\right)$, while all the other stable $\mathrm{Cr}-\mathrm{B}$ phases display hardnesses below $35 \mathrm{GPa}$ (see Table 2), which agrees well with reference experimental data. ${ }^{23,24}$ Other phases with higher hardness have higher formation enthalpy and therefore are metastable or unstable at zero pressure. Most structures with hardness $>40 \mathrm{GPa}$ are pure boron phases. Predicted stable $\mathrm{Cr}-\mathrm{C}$ phases have Vickers hardness below $22 \mathrm{GPa}$ (see Table 2), in agreement with experimental observations. ${ }^{33-35}$ Phases with hardness about 70 $80 \mathrm{GPa}$ are hypothetical metastable carbon allotropes, and the hardest phase in the first Pareto front (Fig. 2e) with the hardness of $89 \mathrm{GPa}$ is diamond with formation enthalpy of $0.028 \mathrm{eV} /$ atom, which agrees well with reference data. ${ }^{60,61}$

Results of Pareto optimization of the Cr-N system show that thermodynamically stable $\mathrm{CrN}$ and $\mathrm{Cr}_{2} \mathrm{~N}$ phases display hardness up to $30 \mathrm{GPa}$. While metastable $\mathrm{CrN}_{2}$ is predicted to be superhard using Gao's and Lyakhov-Oganov models, Chen's model gives a lower hardness (29.5 GPa). For metastable $\mathrm{CrN}_{4}$ structures located in the first and second Pareto fronts (open circles in Fig. 2f) the predicted Lyakhov-Oganov hardness of $\sim 60 \mathrm{GPa}$ is a rare failing of this model: more accurate Chen's model predicts much lower values (see Table 2). For the other phases, agreement between different models of hardness is much better. We also calculated the ideal strength of Pnma-CrN, $\overline{\overline{6}} \mathrm{~m} 2-\mathrm{CrN}, P n n m-\mathrm{Cr}_{2} \mathrm{~N}, R 3 c-\mathrm{CrN}_{4}$ and $P n n m-\mathrm{CrB}_{4}$ phases, to be equal to 38.2, 41.7, 37.3, 24.2 and $52.5 \mathrm{GPa}$, respectively. Ideal strength of Pnnm-CrB 4 was calculated before, ${ }^{22}$ in close agreement with our result. Obtained values of ideal strength correspond well with data for Vickers hardness calculated by Chen's model. 

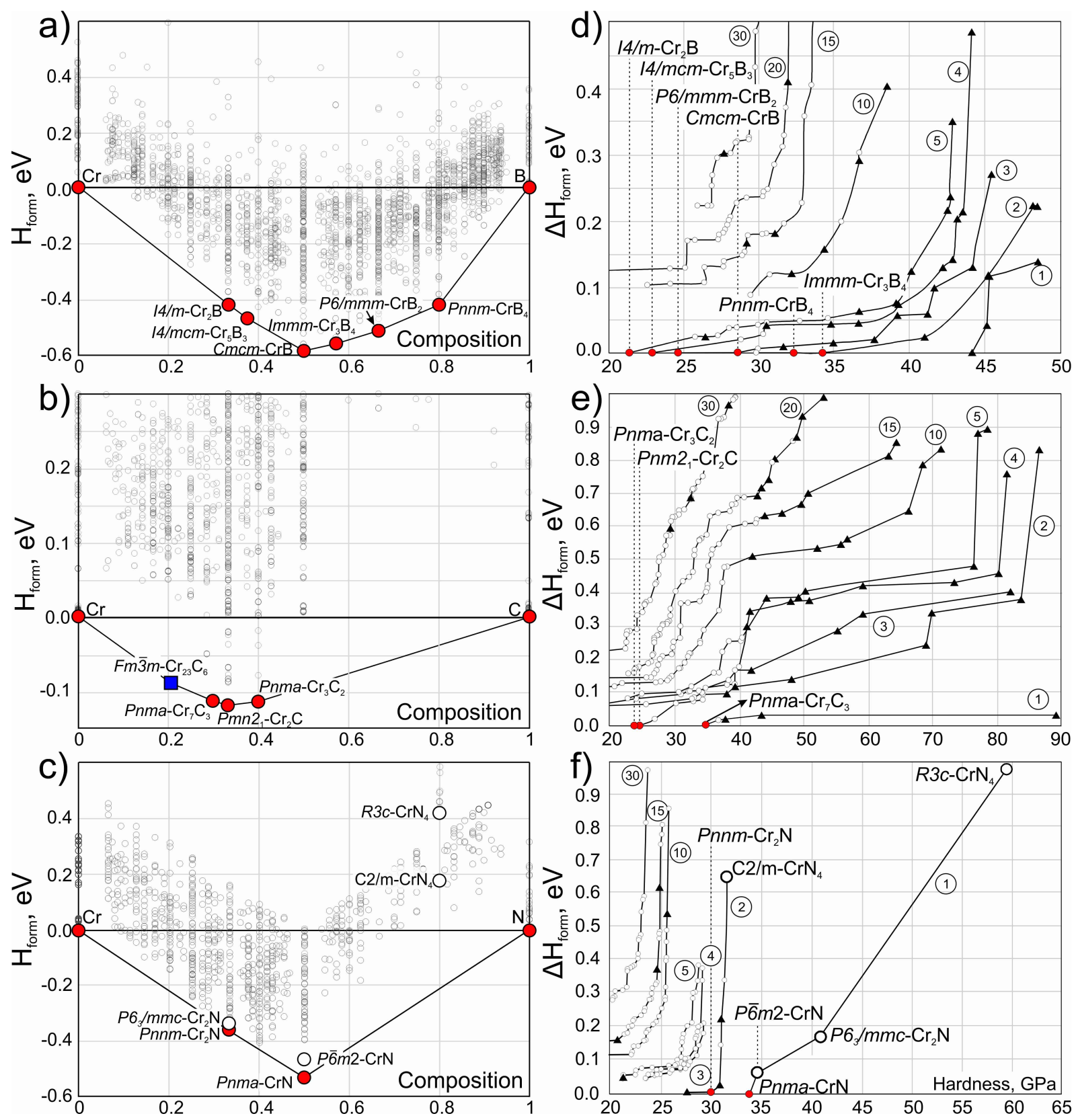

Fig. 2. Convex hull diagrams of a) $\mathrm{Cr}-\mathrm{B}$, b) $\mathrm{Cr}-\mathrm{C}$ and c) $\mathrm{Cr}-\mathrm{N}$ systems and results of Pareto optimization in terms of formation enthalpies and Vickers hardness, computed using the Lyakhov-Oganov model ${ }^{3}$ for d) $\mathrm{Cr}-\mathrm{B}$, e) $\mathrm{Cr}-\mathrm{C}$ and f) $\mathrm{Cr}-\mathrm{N}$ systems. Numbers in circles denote the number of Pareto front. Full circles are stable, open circles - metastable binary phases, full triangles - one-component phases. Square is $F m \overline{3} m-\mathrm{Cr}_{23} \mathrm{C}_{6}$ structure from Ref. ${ }^{32}$

We examined the mechanical properties of considered phases, summarized in Table 2. Considering the $\mathrm{Cr}-\mathrm{B}$ system, the maximum value of bulk modulus was obtained for the $P 6 / m m m-\mathrm{CrB}_{2}$ phase $(278 \mathrm{GPa})$. The $P n n m-\mathrm{CrB}_{4}$ phase displays the largest value of shear modulus $(252 \mathrm{GPa})$, which agrees extremely well with the theoretical and experimental values (267 ${ }^{22}$ and $261 \mathrm{GPa},{ }^{4}$ respectively). Among chromium carbides, the highest bulk modulus is $296 \mathrm{GPa}$ for $\mathrm{Pnma}-\mathrm{Cr}_{3} \mathrm{C}_{2}$ and highest shear modulus is $292 \mathrm{GPa}$ for $P m n 2_{1}-\mathrm{Cr}_{2} \mathrm{C}$ phase. The highest bulk modulus of $\mathrm{Cr}-\mathrm{N}$ phases corresponds to $P \overline{6} m 2-\mathrm{CrN}$ phase $(312 \mathrm{GPa})$. It was expected that this WC-type phase would reveal exceptional mechanical properties (WC has bulk modulus of $439 \mathrm{GPa}^{62}$ ). The bulk moduli of $P n n m$ and $P 6_{3} / m m c$ phases of $\mathrm{Cr}_{2} \mathrm{~N}$ are 232 
and $239 \mathrm{GPa}$, respectively. More detailed information on the elastic tensor of studied phases is summarized in Table S2 (Supporting Information).

Table 2. Mechanical properties of chromium-based materials. Bulk modulus (B), shear modulus $(\mathrm{G})$, hardness calculated using Gao's model $\left(H_{\mathrm{G}}\right)$, Chen's model $\left(H_{\mathrm{C}}\right)$ and Lyakhov-Oganov model $\left(H_{\mathrm{LO}}\right)$, Pugh's modulus ratio $(k=G / B)$ and thermal expansion for $\mathrm{Cr}-\mathrm{N}$ phases at $300 \mathrm{~K}$ $(\alpha)$.

\begin{tabular}{|c|c|c|c|c|c|c|c|c|}
\hline Comp. & $\begin{array}{l}\text { Space } \\
\text { group }\end{array}$ & $B, \mathrm{GPa}$ & $G, \mathrm{GPa}$ & $\begin{array}{l}H_{\mathrm{G}} \\
\mathrm{GPa}\end{array}$ & $\begin{array}{l}H_{\mathrm{C}} \\
\mathrm{GPa}\end{array}$ & $\begin{array}{l}H_{\mathrm{LO}} \\
\mathrm{GPa}\end{array}$ & $k$ & $\alpha, 10^{-6} \mathrm{~K}^{-1}$ \\
\hline $\mathrm{Cr}_{2} \mathrm{~B}$ & $I 4 / m$ & 269.5 & 178.3 & 28.1 & 22.6 & 21.5 & 0.66 & - \\
\hline $\mathrm{Cr}_{5} \mathrm{~B}_{3}$ & $\begin{array}{l}4 \\
/ \mathrm{mcm}\end{array}$ & 250.7 & 189.4 & 26.2 & 27.9 & 22.9 & 0.76 & - \\
\hline $\mathrm{CrB}$ & $\mathrm{Cmcm}$ & $\begin{array}{c}255.3 \\
(\text { theor: } 304.8)^{21} \\
(\text { exp: 269) }\end{array}$ & $\begin{array}{c}209.5 \\
\text { (theor: } \\
225.4)^{21}\end{array}$ & \multicolumn{3}{|c|}{$(\exp : 19.2-23)^{21,23}$} & 0.82 & - \\
\hline & & & & 32.9 & 28.1 & 34.1 & 0.73 & - \\
\hline $\mathrm{Cr}_{3} \mathrm{~B}_{4}$ & Immm & $2 / 0.0$ & 202.8 & \multicolumn{3}{|c|}{$(\text { exp: } 20.9-23.0)^{23}$} & & \\
\hline $\mathrm{CrB}_{4}$ & Pnnm & $\begin{array}{c}252.6 \\
(\text { theor: } 265)^{4} \\
(\text { exp: 232) }\end{array}$ & $\begin{array}{c}251.8 \\
\text { (theor: } \\
267^{22} \text { ) } \\
(\mathrm{exp}: \\
261^{4} \text { ) }\end{array}$ & $\begin{array}{r}36.6 \\
\text { (theor: } \\
46.8)^{5} \\
(\mathrm{e}\end{array}$ & $\begin{array}{r}47.6 \\
\text { (theor: } \\
48)^{4} \\
28.6-\end{array}$ & 32.9 & 0.83 & - \\
\hline $\mathrm{CrB}_{2}$ & $\begin{array}{l}P 6 \\
/ m m m\end{array}$ & $\begin{array}{c}278.4 \\
{\text { (theor: } 298)^{5}} \\
(\text { exp: 228) }\end{array}$ & $\begin{array}{l}156.4 \\
\text { (theor: } \\
172)^{5} \\
\end{array}$ & \multicolumn{3}{|c|}{ (exp: $23.1-15.8)^{24}$} & 0.56 & - \\
\hline $\mathrm{Cr}_{7} \mathrm{C}_{3}$ & Pnma & $\begin{array}{c}264.6 \\
\text { (theor: } 300.6)^{32}\end{array}$ & $\begin{array}{l}104.4 \\
\text { (theor: } \\
118)^{32}\end{array}$ & $\begin{array}{c}25.1 \\
\text { (theor: } 1\end{array}$ & $\begin{array}{c}7.2 \\
\left.3^{32}\right)(\mathrm{e} \\
7,{ }^{63} 16\end{array}$ & $\begin{array}{c}33.1 \\
16.9,{ }^{34}\end{array}$ & 0.44 & - \\
\hline $\mathrm{Cr}_{2} \mathrm{C}$ & $P m n 2_{1}$ & 292.8 & 184.5 & 27.3 & 21.6 & 24.5 & 0.63 & \\
\hline $\mathrm{Cr}_{3} \mathrm{C}_{2}$ & Pnma & $\begin{array}{c}296.2 \\
\text { (theor: } 312.9)^{32}\end{array}$ & $\begin{array}{l}163.6 \\
\text { (theor: } \\
162)^{56}\end{array}$ & \multicolumn{3}{|c|}{$\begin{array}{c}\text { (theor: } 20.9^{32} \text { ) } \\
\text { (exp: } 18.9,{ }^{63} 18.3^{64} \text { ) }\end{array}$} & 0.55 & - \\
\hline $\begin{array}{l}\mathrm{Cr}_{23} \mathrm{C}_{6} \\
\text { Ref. }^{32}\end{array}$ & $F m \overline{3} m$ & $\begin{array}{c}263.4 \\
{\text { (theor: } 282.3)^{32}}^{\text {(exp: } 300)^{56}} \\
\end{array}$ & 178.3 & $\begin{array}{l}24.8 \\
\text { (theor: }\end{array}$ & $\begin{array}{r}14.1 \\
3.2,{ }^{32} \mathrm{e}\end{array}$ & $\begin{array}{r}21.5 \\
\left.15^{63}\right)\end{array}$ & 0.53 & - \\
\hline $\begin{array}{c}\mathrm{CrN} \\
(U-J=1 \mathrm{eV}) \\
\end{array}$ & Pnma & $\begin{array}{c}221.4 \\
(\exp : 262)^{39}\end{array}$ & 152.1 & 35.8 & 21.4 & 34.8 & 0.72 & 2.01 \\
\hline $\begin{array}{c}\mathrm{CrN} \\
(U-J=1 \mathrm{eV})\end{array}$ & $P \overline{6} m 2$ & 312.6 & 220.5 & 36.8 & 28.2 & 34.6 & 0.74 & 2.14 \\
\hline $\mathrm{Cr}_{2} \mathrm{~N}$ & Pnnm & 235.4 & 133.1 & 31.8 & 15.0 & 31.3 & 0.59 & 2.05 \\
\hline $\mathrm{Cr}_{2} \mathrm{~N}$ & $\begin{array}{l}P 6_{3} \\
/ m m c\end{array}$ & 239.8 & 116.1 & 37.9 & 11.0 & 41.0 & 0.47 & 2.55 \\
\hline
\end{tabular}




\begin{tabular}{|c|c|c|c|c|c|c|c|c|}
\hline Comp. & $\begin{array}{l}\text { Space } \\
\text { group }\end{array}$ & $B, \mathrm{GPa}$ & $G, \mathrm{GPa}$ & $\begin{array}{l}H_{\mathrm{G}} \\
\mathrm{GPa}\end{array}$ & $\begin{array}{l}H_{\mathrm{C}} \\
\mathrm{GPa}\end{array}$ & $\begin{array}{l}H_{\mathrm{LO}}, \\
\mathrm{GPa}\end{array}$ & $k$ & $\alpha, 10^{-6} \mathrm{~K}^{-1}$ \\
\hline $\begin{array}{c}\mathrm{CrN}_{4} \\
(U-J=1 \mathrm{eV})\end{array}$ & $C 2 / m$ & 26.7 & 21.8 & 46.8 & 2.2 & 31.6 & 0.82 & 6.52 \\
\hline $\begin{array}{c}\mathrm{CrN}_{4} \\
(U-J=1 \mathrm{eV})\end{array}$ & $R 3 c$ & 176.6 & 101.1 & 57.2 & 12.5 & 59.5 & 0.59 & 1.39 \\
\hline $\begin{array}{l}\mathrm{CrN}_{2} \\
\text { Ref. }^{6}\end{array}$ & $P \overline{6} m 2$ & $\begin{array}{c}273.6 \\
(\text { theor: } 366)^{6}\end{array}$ & $\begin{array}{l}235.3 \\
\text { (theor: } \\
256)^{6}\end{array}$ & $\begin{array}{c}46.3 \\
\text { (theor: } \\
45.9)^{6}\end{array}$ & 29.5 & 44.4 & 0.69 & - \\
\hline
\end{tabular}

We paid more attention to the less studied $\mathrm{Cr}-\mathrm{N}$ system and its stable and metastable phases. Part of the interest in new nitride phases comes from the possibility of reduction of the pressure of nitrogen polymerization for synthesis of high energy-density materials. It is necessary to compress pure nitrogen to $>110 \mathrm{GPa}^{65}$ to obtain a polymeric phase, and such a high pressure precludes any practical applications. One of the possible ways to reduce the polymerization pressure is to combine nitrogen with metal ions (such as chromium, explored here). Indeed, it was found previously that presence of sodium reduces the polymerization pressure of nitrogen down to $\sim 80 \mathrm{GPa}$ in the compound $\mathrm{NaN}_{3}$. ${ }^{66}$

In the convex hull diagram of the $\mathrm{Cr}-\mathrm{N}$ system, three different composition of $\mathrm{CrN}_{\mathrm{x}}$ were found with $\mathrm{x}=0.5,1,4$. The X-ray diffraction (XRD) patterns are shown in Fig. 3 a. One can see good agreement between simulated and experimental ${ }^{49}$ XRD patterns of Pnma-CrN, shown in the (i) panel of Fig. 3 a. We found that XRD pattern of the predicted $P n n m-\mathrm{Cr}_{2} \mathrm{~N}$ agrees perfectly with experimental data from Ref. ${ }^{49}$ (see Fig. 3 a, (ii) panel). This phase, observed in several experimental works, ${ }^{47-52}$ remained structurally unresolved until now - but here we finally determine its crystal structure: Pnnm phase is isostructural to calcium chloride $\left(\mathrm{CaCl}_{2}\right){ }^{67}$ and post-stishovite $\mathrm{SiO}_{2}{ }^{68}$ (see Fig. 3 b).

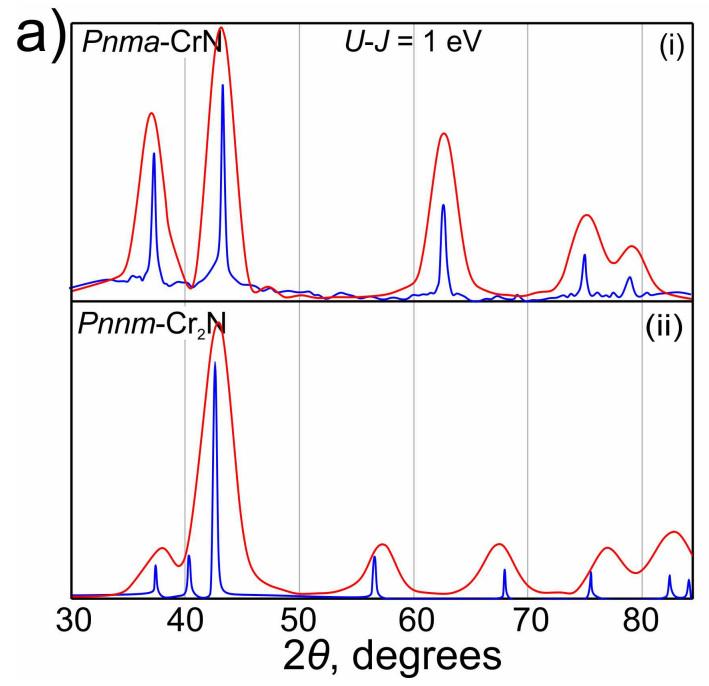

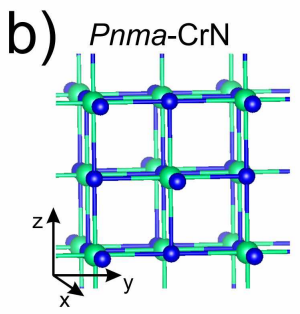
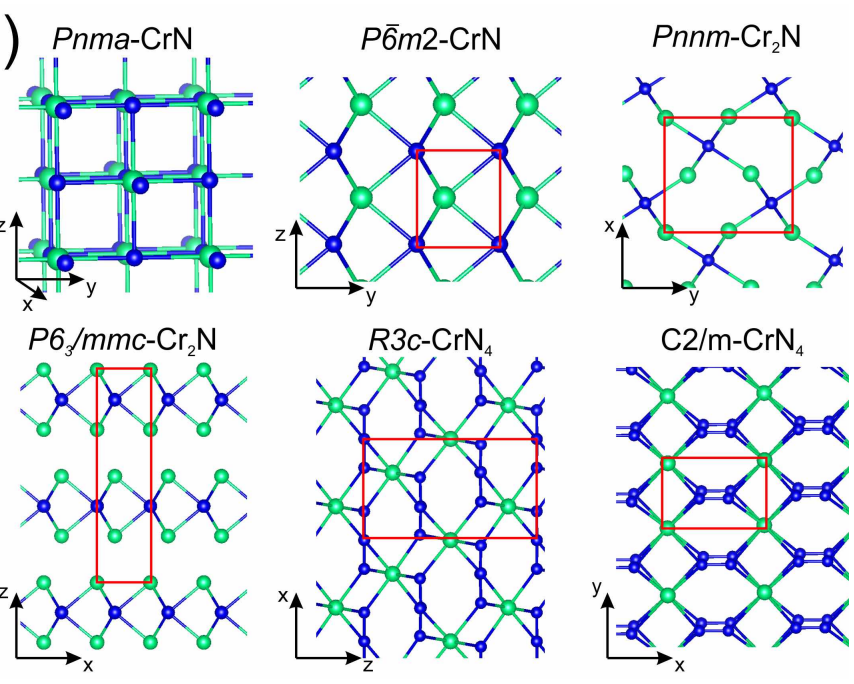

$\mathrm{C} 2 / \mathrm{m}-\mathrm{CrN}_{4}$

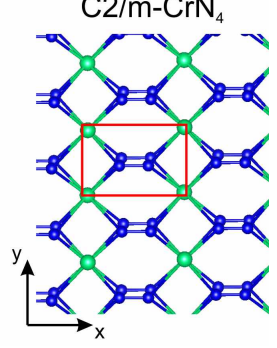

Fig. 3. a) Simulated X-ray diffraction pattern (XRD) with $\lambda=1.54 \AA$. Blue lines are experimental XRD patterns from Ref. ${ }^{49}$; b) Crystal structures of $\mathrm{CrN}, \mathrm{Cr}_{2} \mathrm{~N}$ and $\mathrm{CrN}_{4}$ phases. Green spheres $-\mathrm{Cr}$ atoms, blue $-\mathrm{N}$ atoms.

Pnma-CrN phase has a NaCl-type structure with an orthorhombic distortion due to antiferromagnetic ordering, while predicted $\overline{6} m 2-\mathrm{CrN}$ is isostructural to tungsten carbide (WC). Structural similarity suggests that $P \overline{6} m 2-\mathrm{CrN}$ may have outstanding mechanical properties similar to those of WC. Another phase of $\mathrm{Cr}_{2} \mathrm{~N}$ with a space group $P 6_{3} / m m c$ has 
layered structure and is isostructural to layered transition metal dichalcogenides (TMDCs), shown in Fig. 3b. This phase could be considered as a possible material for isolation of single layer of $\mathrm{Cr}_{2} \mathrm{~N}$ using micromechanical cleavage. ${ }^{69,70}$ Newly predicted $\mathrm{CrN}_{4}$ is found in two forms, with space groups $R 3 c$ and $C 2 / m$; their structures are shown in Fig. 3b. Detailed structural parameters and energies above the convex hull (see Fig. 2c) of considered phases are summarized in Table 3.

Computed phonon densities of states for the Pnma and $P \overline{6} \mathrm{~m} 2 \mathrm{CrN}$ phases at zero pressure are shown in the (i) panel of Fig. 4 a and display the absence of imaginary phonon frequencies, which manifests about dynamical stability of both $\mathrm{CrN}$ phases. The phase transition pathway from Pnma to $P \overline{6} m 2 \mathrm{CrN}$ was modeled by the VCNEB method ${ }^{71}$ and shown in Fig. S1 (see Supporting Information for details).

Table 3. Structural parameters of $\mathrm{Cr}-\mathrm{N}$ phases.

\begin{tabular}{|c|c|c|c|c|c|c|c|c|}
\hline Comp. & $\begin{array}{c}\text { Lattice } \\
\text { parameters, } \AA\end{array}$ & $\begin{array}{c}\mathrm{V}, \\
\AA^{3} / \text { unit }\end{array}$ & $\begin{array}{c}\rho, \\
\mathrm{g} / \mathrm{cm}^{3}\end{array}$ & \multicolumn{4}{|c|}{ Positions } & $\begin{array}{c}\Delta \mathrm{H}_{\text {form }}, \\
\mathrm{eV}\end{array}$ \\
\hline $\begin{array}{c}\text { Pnma } \\
\mathrm{CrN} \\
(U-J=1 \mathrm{eV})\end{array}$ & $\begin{array}{c}\mathrm{b}=4.17 \\
\left(\exp : \mathrm{a}=4.148^{37}\right. \\
\left.\mathrm{a}=4.1513^{39}\right)\end{array}$ & 18.33 & 5.97 & $\begin{array}{l}\mathrm{Cr} \\
\mathrm{N}\end{array}$ & $\begin{array}{l}0.0 \\
1 / 2\end{array}$ & $\begin{array}{l}0.0 \\
1 / 2\end{array}$ & $\begin{array}{l}0.0 \\
1 / 2\end{array}$ & 0.0 \\
\hline $\begin{array}{c}P \overline{6} m 2 \\
\mathrm{CrN} \\
(U-J=1 \mathrm{eV}) \\
\end{array}$ & $\begin{array}{c}\mathrm{a}=\mathrm{b}=2.67 \\
\mathrm{c}=2.59\end{array}$ & 16.05 & 6.82 & $\begin{array}{l}\mathrm{Cr} \\
\mathrm{N}\end{array}$ & $\begin{array}{l}0.0 \\
1 / 3\end{array}$ & $\begin{array}{l}0.0 \\
2 / 3\end{array}$ & $\begin{array}{l}0.0 \\
1 / 2\end{array}$ & 0.066 \\
\hline $\begin{array}{c}n n m \\
\mathrm{Cr}_{2} \mathrm{~N} \\
\end{array}$ & $\begin{array}{c}\mathrm{a}=4.79, \mathrm{~b}=4.33 \\
\mathrm{c}=2.79\end{array}$ & 29.12 & 7.53 & $\begin{array}{l}\mathrm{Cr} \\
\mathrm{N}\end{array}$ & $\begin{array}{c}0.164 \\
0.0\end{array}$ & $\begin{array}{c}0.242 \\
1 / 2 \\
\end{array}$ & $\begin{array}{l}0.0 \\
1 / 2 \\
\end{array}$ & 0.0 \\
\hline $\begin{array}{c}P 6_{3} / m m c \\
\quad \mathrm{Cr}_{2} \mathrm{~N} \\
\end{array}$ & $\begin{array}{c}\mathrm{a}=\mathrm{b}=2.67 \\
\mathrm{c}=9.19\end{array}$ & 28.29 & 6.93 & $\begin{array}{l}\mathrm{Cr} \\
\mathrm{N}\end{array}$ & $\begin{array}{l}0.0 \\
0.0\end{array}$ & $\begin{array}{l}-0.172 \\
-0.162 \\
\end{array}$ & $\begin{array}{c}-0.112 \\
1 / 4 \\
\end{array}$ & 0.005 \\
\hline $\begin{array}{c}C 2 / m \\
\mathrm{CrN}_{4} \\
(U-J=1 \mathrm{eV})\end{array}$ & $\begin{array}{c}\mathrm{a}=7.64, \mathrm{~b}=7.45 \\
\mathrm{c}=3.91\end{array}$ & 44.41 & 3.32 & $\begin{array}{l}\mathrm{Cr} \\
\mathrm{Cr} \\
\mathrm{N} \\
\mathrm{N} \\
\mathrm{N}\end{array}$ & $\begin{array}{c}0.0 \\
0.0 \\
1 / 2 \\
0.285 \\
-0.279\end{array}$ & $\begin{array}{c}0.0 \\
1 / 2 \\
0.28 \\
0.0 \\
0.0\end{array}$ & $\begin{array}{c}0.0 \\
0.0 \\
-0.349 \\
0.371 \\
0.328\end{array}$ & 0.364 \\
\hline $\begin{array}{c}R 3 c \\
\mathrm{CrN}_{4} \\
(U-J=1 \mathrm{eV})\end{array}$ & $\begin{array}{c}\mathrm{a}=\mathrm{b}=4.56 \\
\mathrm{c}=13.81\end{array}$ & 49.74 & 4.18 & $\begin{array}{l}\mathrm{Cr} \\
\mathrm{N} \\
\mathrm{N}\end{array}$ & $\begin{array}{c}0.0 \\
0.339 \\
0.0\end{array}$ & $\begin{array}{c}0.0 \\
0.376 \\
0.0\end{array}$ & $\begin{array}{c}-0.157 \\
1 / 4 \\
-0.421\end{array}$ & 0.689 \\
\hline $\begin{array}{c}P \overline{6} m 2 \\
\mathrm{CrN}_{2} \text { Ref. }\end{array}$ & $\begin{array}{c}a=b=2.68 \\
c=3.67 \\
(a=b=2.72 \\
c=3.71)^{6}\end{array}$ & $\begin{array}{c}22.76 \\
(23.86)^{6}\end{array}$ & 4.24 & $\begin{array}{l}\mathrm{Cr} \\
\mathrm{N}\end{array}$ & $\begin{array}{l}0.0 \\
2 / 3\end{array}$ & $\begin{array}{l}0.0 \\
1 / 3\end{array}$ & $\begin{array}{c}0.0 \\
0.682\end{array}$ & 0.055 \\
\hline
\end{tabular}

Both of the $\mathrm{Cr}_{2} \mathrm{~N}$ phases (with space groups Pnnm and $P 6_{3} / m m c$ ) were found to be dynamically stable (see (ii) panel of Fig. 4a), the formed being energetically slightly more stable and matching perfectly the experimental XRD patterns (Fig. 3a). It is important to note that for metallic $\mathrm{Cr}_{2} \mathrm{~N}$ phases we did not use the Hubbard $U$-term correction, in contrast to $\mathrm{CrN}$ and $\mathrm{CrN}_{4}$ phases. Detailed information on the choice of $U-J$ parameter described in Supporting Information. 
Two lowest-enthalpy $\mathrm{CrN}_{4}$ phases that emerged from our evolutional searches are in fact high energy-density materials with polymeric nitrogen chains with 2 atoms $\left(C 2 / m-\mathrm{CrN}_{4}\right)$ and flat triangular $\mathrm{NN}_{3}$-groups (similar to $\mathrm{NO}_{3}$-groups, with oxygens replaced by nitrogens; $R 3 c-\mathrm{CrN}_{4}$ is structurally similar to calcite $\mathrm{CaCO}_{3}$ and $\mathrm{NaNO}_{3}$ ) in the repeat unit. The effect of electron correlation is important in these phases: e.g., they are both dynamically unstable at $U-J=0 \mathrm{eV}$ (see Fig. S2), and dynamically stable with $U-J=1 \mathrm{eV}$ (see Fig. 4a, (iii) panel).

Both $\mathrm{CrN}_{4}$ phases are metastable at zero pressure and even have positive enthalpies of formation (see Fig. 2c). However, at pressures above $5 \mathrm{GPa}$ the formation enthalpy of $\mathrm{C} 2 / \mathrm{m}$ phase becomes negative (above $7.5 \mathrm{GPa}$ for $R 3 c-\mathrm{CrN}_{4}$ ), and at the pressure of $17 \mathrm{GPa}$ the phase transition $C 2 / m \rightarrow R 3 c$ occurs. This means that $R 3 c$ phase of $\mathrm{CrN}_{4}$ should be synthesizable under pressure more than $7 \mathrm{GPa}$. Calculations of phase transition pressure with $U-J$ from 0 to $5 \mathrm{eV}$ gave the phase transition pressure in a region from 12 to $24 \mathrm{GPa}$ at $0 \mathrm{~K}$. At pressures above $\sim 15 \mathrm{GPa} \mathrm{CrN}_{4}$ becomes thermodynamically stable (see Fig. 5).

Containing polymeric nitrogen chains, at normal conditions $\mathrm{CrN}_{4}$ can be a high energydensity material. We estimated the energy density of $\mathrm{CrN}_{4}$ (equal to the enthalpy of reaction $\mathrm{CrN}_{4} \rightarrow \mathrm{CrN}+3 / 2 \mathrm{~N}_{2}$ ) to be equal to 1.96 and $3.51 \mathrm{MJ} / \mathrm{kg}$ for $C 2 / \mathrm{m}$ and $R 3 c$ phases, respectively. For comparison, the energy density of TNT (trinitrotoluene) is $4.6 \mathrm{MJ} / \mathrm{kg},{ }^{72}$ for gunpowder $3 \mathrm{MJ} / \mathrm{kg}$, for nitroglycerin $6.6 \mathrm{MJ} / \mathrm{kg},{ }^{73}$ for lead azide $2.6 \mathrm{MJ} / \mathrm{kg}$. ${ }^{74}$ Our results show that the presence of metals (such as $\mathrm{Cr}$ ) lowers the pressure of polymerization of nitrogen, even though with reduced (but still high) energy density.
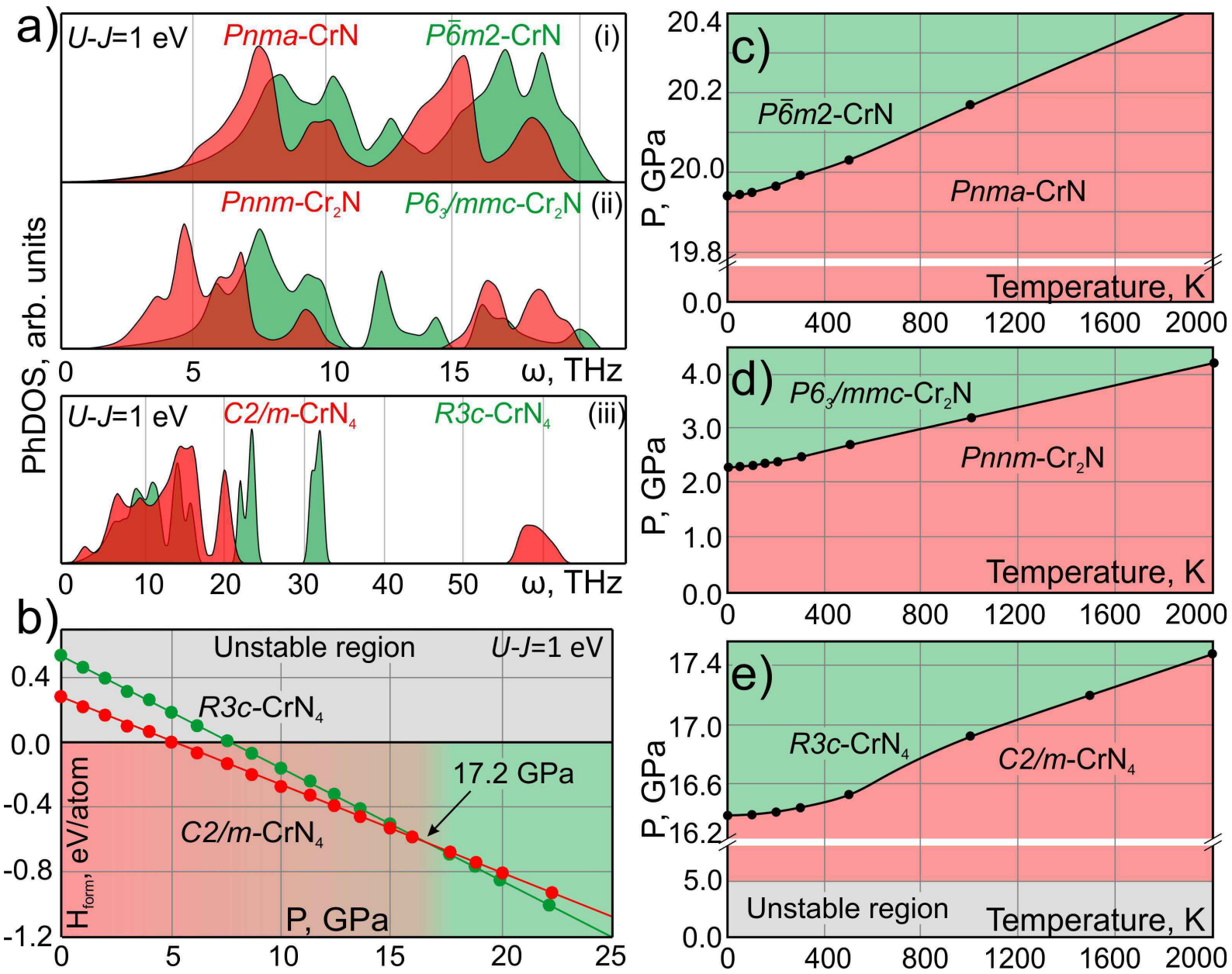

Fig. 4. a) Phonon densities of states of $\mathrm{Cr}-\mathrm{N}$ phases; b) Dependence of the enthalpy of formation on the external pressure for $\mathrm{CrN}_{4}$ phases. Phase diagrams of c) $\left.\mathrm{CrN}, \mathrm{d}\right) \mathrm{Cr}_{2} \mathrm{~N}$ and e) $\mathrm{CrN}_{4}$. 
Conditions for experimental synthesis of $\mathrm{CrN}$ phases were estimated by computing phase diagrams, shown in Fig. 4c, where Pnma $\rightarrow P \overline{6} m 2$ phase transition pressure at $0 \mathrm{~K}$ equals to 19.9 GPa, which is readily achievable in experiments. The phase boundary between Pnnm and $\mathrm{PG}_{3} / \mathrm{mmc}$ phases of $\mathrm{Cr}_{2} \mathrm{~N}$ is shown in Fig. $4 \mathrm{~d}$, where Pnnm phase undergoes phase transition to $P 6_{3} / m m c$ under $2.2 \mathrm{GPa}$ at $0 \mathrm{~K}$. Thus, it should be possible to synthesize new $\mathrm{Cr}_{2} \mathrm{~N}$ phase with layered structure at very mild pressures, and this phase should remain dynamically stable upon decompression to ambient pressure. Computed phase diagram of the pressure-induced $C 2 / m \rightarrow R 3 c$ phase transition of $\mathrm{CrN}_{4}$ is shown in Fig. 4 e, where the phase transition pressure equals to $16.4 \mathrm{GPa}$ at $0 \mathrm{~K}$.

The convex hull diagrams of $\mathrm{Cr}-\mathrm{N}$ phases were calculated at the pressures of 10, 20 and $30 \mathrm{GPa}$ as shown in Fig. 5. We see the same stable compositions as at zero pressure, and in addition $\mathrm{CrN}_{4}$ becomes thermodynamically stable at pressures above $\sim 15 \mathrm{GPa}$.
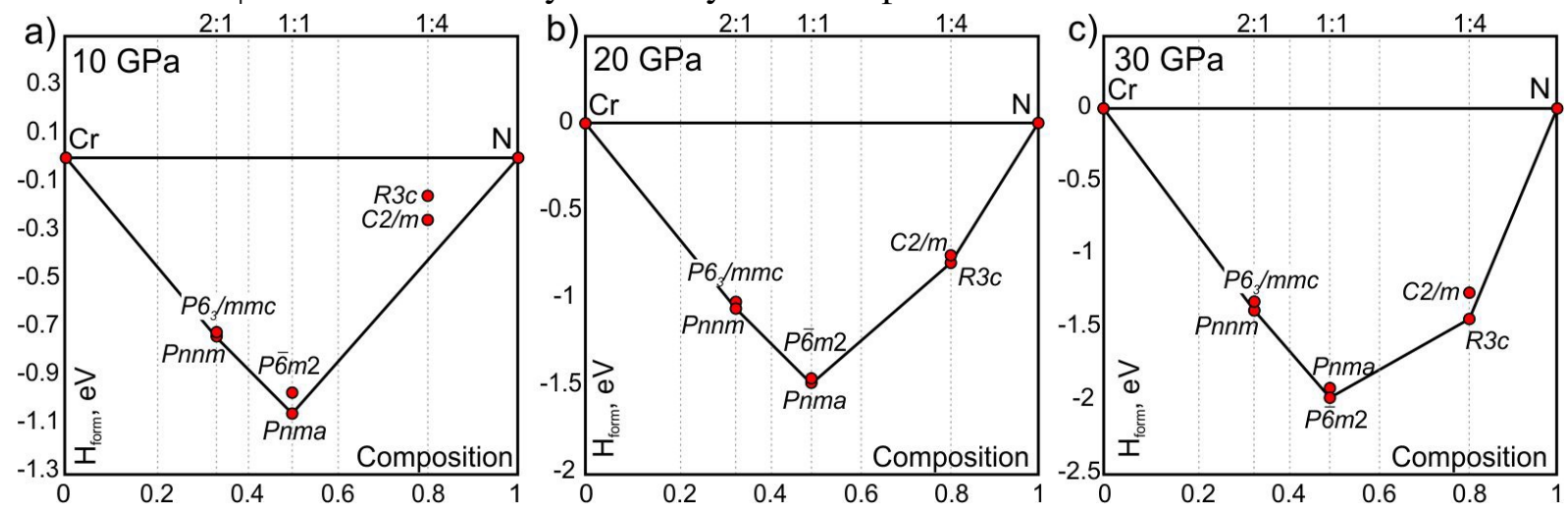

Fig. 5. Convex hull diagrams for Cr-N system at a) $10 \mathrm{GPa}$, b) $20 \mathrm{GPa}$, c) $30 \mathrm{GPa}$.

\section{Conclusions}

In this work, we studied new phases in the $\mathrm{Cr}-\mathrm{B}, \mathrm{Cr}-\mathrm{C}$ and $\mathrm{Cr}-\mathrm{N}$ systems using global optimization combined with Pareto optimization technique, which allows us to search for new stable materials with outstanding hardness. We found all experimentally known chromium borides, carbides and nitrides (except $\mathrm{Cr}_{23} \mathrm{C}_{6}$ with a relatively large unit cell) and predicted several new phases. Hardness of the predicted phases was calculated using different models and compared with available experimental and theoretical data. Overall, chromium borides are shown to possess highest hardnesses and largest negative enthalpies of formation, compared to carbides and nitrides. The only thermodynamically stable superhard compound here is $\mathrm{CrB}_{4}$ with the predicted hardness of $\sim 48 \mathrm{GPa}$, in excellent agreement with experiments. ${ }^{24}$ Detailed investigation of the less studied $\mathrm{Cr}-\mathrm{N}$ system was carried out. The previously unresolved crystal structure of $\mathrm{Cr}_{2} \mathrm{~N}$ was shown to be of anti-CaCl $\mathrm{Ca}_{2}$ type (space group Pnnm). We found that synthesis of $\mathrm{CrN}_{4}$ phases with energy density up to $3 \mathrm{MJ} / \mathrm{kg}$ and featuring polymeric nitrogen chains can be realized by applying pressure above $\sim 15 \mathrm{GPa}$, much lower than $110 \mathrm{GPa}$ needed to synthesize pure polymeric nitrogen.

\section{Methods}

Stable phases in the $\mathrm{Cr}-\mathrm{B}, \mathrm{Cr}-\mathrm{C}$ and $\mathrm{Cr}-\mathrm{N}$ systems were predicted using first-principles variable-composition evolutionary algorithm (EA) in coupling with Pareto optimization technique as implemented in the USPEX code. ${ }^{75-80}$ Here, evolutionary searches were combined with structure relaxations using density functional theory (DFT) ${ }^{81,82}$ within the spin-polarized generalized gradient approximation (Perdew-Burke-Ernzerhof functional), ${ }^{83}$ as implemented 
in the VASP ${ }^{84-86}$ package. The plane-wave energy cutoff was set to $500 \mathrm{eV}$. For studying phase transition pathways of $\mathrm{CrN}$ phases, we used the variable-cell nudged elastic band method (VCNEB) ${ }^{71}$ as implemented in the USPEX code. In order to take into account strong electron correlations between the localized $3 d$-electrons of $\mathrm{Cr}$ atoms, the GGA $+U$ approach within Dudarev's formulation ${ }^{87,88}$ was applied in some cases (unless explicitly stated otherwise, $U$ $J=0$ was used). For Brillouin zone sampling, $\Gamma$-centered $k$-meshes of $2 \pi \times 0.05 \AA^{-1}$ resolution were used, ensuring the convergence of total energies to better than $10^{-6} \mathrm{eV} /$ atom. During structure searches, the first generation was produced randomly within 16 atoms in the unit cell, and succeeding generations were obtained by applying heredity (40\%), softmutation $(20 \%)$, transmutation $(20 \%)$ operations, respectively and $20 \%$ of each generation was produced using random symmetry generator. Two types of variable-composition calculations were performed in each binary system $(\mathrm{Cr}-\mathrm{B}, \mathrm{Cr}-\mathrm{C}, \mathrm{Cr}-\mathrm{N})$ : (1) optimizing stability and (2) jointly optimizing stability and hardness with Pareto ranking of all structures (in the latter case, the fitness of each structure was taken to be equal to the order of its Pareto front).

For the predicted crystal structures, we performed high-quality calculations of their physical properties. Crystal structures were relaxed until the maximum net force on atoms became less than $0.01 \mathrm{eV} / \AA$. The Monkhorst-Pack scheme ${ }^{89}$ was used to sample the Brillouin zone, using 12.12.12 (Pnma-CrN), 8.8.10 (Pnnm-Cr $\left.{ }_{2} \mathrm{~N}\right), 12 \cdot 12 \cdot 8\left(\mathrm{C} 2 / \mathrm{m}-\mathrm{CrN}_{4}\right), 6 \cdot 6 \cdot 6$ $\left(F m \overline{3} m-\mathrm{Cr}_{23} \mathrm{C}_{6}\right), 8 \cdot 8 \cdot 8 \quad\left(\mathrm{Pmn2}_{1}-\mathrm{Cr}_{2} \mathrm{C}\right), 8 \cdot 6 \cdot 4 \quad\left(\mathrm{Pnma}_{-}-\mathrm{Cr}_{3} \mathrm{C}_{2}\right), 8 \cdot 6 \cdot 4 \quad\left(\mathrm{Pnma}_{-} \mathrm{Cr}_{7} \mathrm{C}_{3}\right), 8 \cdot 8 \cdot 8$ (I4/m-Cr $2 \mathrm{~B}), 8 \cdot 8 \cdot 6\left(\mathrm{Immm}-\mathrm{Cr}_{3} \mathrm{~B}_{4}\right), 8 \cdot 8 \cdot 6\left(\mathrm{I} 4 / \mathrm{mcm}-\mathrm{Cr}_{5} \mathrm{~B}_{3}\right), 8 \cdot 8 \cdot 8$ (Cmcm-CrB), 6.8.6 (Pnnm$\left.\mathrm{CrB}_{4}\right)$, while for hexagonal lattices the $\Gamma$-centered grid was used with $k$-points mesh of $12 \cdot 12 \cdot 12$ $\left(P 6 / m m m-\mathrm{CrB}_{2}\right), 12 \cdot 12 \cdot 12(P \overline{6} m 2-\mathrm{CrN}), 8 \cdot 8 \cdot 4\left(P 6_{3} / m m c-\mathrm{Cr}_{2} \mathrm{~N}\right), 8 \cdot 8 \cdot 6\left(R 3 c-\mathrm{CrN}_{4}\right)$.

The hardness was estimated according to three models of hardness: Lyakhov-Oganov model $^{3}\left(H_{\mathrm{LO}}\right)$, Gao's model ${ }^{90}\left(H_{\mathrm{G}}\right)$ and Chen's model ${ }^{59}\left(H_{\mathrm{C}}\right)$, in the latter hardness is calculated using the following relation:

$$
H_{C}=2 \cdot\left(k^{2} \cdot G\right)^{0.585}-3
$$

where $k$ is the Pugh ratio $(k=G / B)$, and $G$ is shear modulus and $B$ the bulk modulus. The bulk and shear moduli were calculated via Voigt-Reuss-Hill (VRH) averaging. ${ }^{41}$

The phase diagram was obtained using the computed Gibbs free energies $G$ of the relevant phases in the quasiharmonic approximation: ${ }^{91}$

$$
G(P, T)=E_{0}(V)+F_{v i b}(T, V)+P(T, V) V,
$$

where $E_{0}$ is the total energy from the DFT calculations and $F_{v i b}$ is vibrational Helmholtz free energy calculated from the following relation:

$$
F_{v i b}(T, V)=k_{B} T \int_{\Omega} g(\omega(V)) \ln \left[1-\exp \left(-\frac{\hbar \omega(V)}{k_{B} T}\right)\right] d \omega+\frac{1}{2} \int g(\omega(V)) \hbar \omega d \omega,
$$

and pressure is

$$
P(T, V)=-\frac{\partial\left(E_{0}(V)+F_{v i b}(T, V)\right)}{\partial V} .
$$

Here $g(\omega(V))$ is the phonon density of states at the given pressure, calculated from forces on atoms with atomic finite displacements using density-functional perturbation theory (DFPT) implemented in the VASP package, ${ }^{84-86}$ and the phonon frequencies are calculated from the force constants using the PHONOPY package. ${ }^{92,93}$ Once Gibbs free energies are computed, phase equilibrium lines on the phase diagram are determined as loci of points where free energies of phases are equal. The chosen approach is validated by a number of reference 
papers ${ }^{91,94-99}$ that calculated the phase diagram $P(T)$ of various materials. Crystal structures of predicted phases were generated using VESTA software. ${ }^{100}$

\section{Acknowledgements}

The work was supported by Russian Science Foundation (№ 16-13-10459). Calculations were performed on the Rurik supercomputer at MIPT. The authors thank Prof. Vladislav A. Blatov for help in the application of TOPOS package for design of the initial transition pathway in $\mathrm{CrN}$ (see Supporting Information).

Supporting Information Available: Detailed description of the mechanism of the phase transition of $\mathrm{CrN}$ from NaCl-type to WC-type structure. The details of calculations of $\mathrm{Cr}-\mathrm{N}$ system with $D F T+U$ approach. Calculated elastic tensor of studied $\mathrm{Cr}-\mathrm{C}, \mathrm{Cr}-\mathrm{B}$ and $\mathrm{Cr}-\mathrm{N}$ systems compared with reference data. Electronic properties of $\mathrm{Cr}-\mathrm{N}$ phases.

\section{REFERENCES}

(1) Liu, A. Y.; Cohen, M. L. Prediction of New Low Compressibility Solids. Science 1989, 245, 841-842.

(2) Niu, C.; Lu, Y. Z.; Lieber, C. M. Experimental Realization of the Covalent Solid Carbon Nitride. Science 1993, 261, 334-337.

(3) Lyakhov, A. O.; Oganov, A. R. Evolutionary Search for Novel Superhard Materials: Methodology and Applications to Forms of Carbon and TiO2. Phys. Rev. B 2011, 84, 92103.

(4) Niu, H.; Wang, J.; Chen, X.-Q.; Li, D.; Li, Y.; Lazar, P.; Podloucky, R.; Kolmogorov, A. N. Structure, Bonding, and Possible Superhardness of CrB4. Phys. Rev. B 2012, 85, 144116

(5) Zhong, M.-M.; Huang, C.; Tian, C.-L. The Structural Stabilities, Mechanical Properties and Hardness of Chromium Tetraboride: Compared with Low-B Borides. Int. J. Mod. Phys. B 2016, 1650201.

(6) Zhao, Z.; Bao, K.; Tian, F.; Duan, D.; Liu, B.; Cui, T. Potentially Superhard Hep CrN2 Compound Studied at High Pressure. Phys. Rev. B 2016, 93, 214104.

(7) Pearson, W. B. Chapter XI - An Alphabetical Index Of Work On Metals And Alloys. In A Handbook of Lattice Spacings and Structures of Metals and Alloys; International Series of Monographs on Metal Physics and Physical Metallurgy; Pergamon, 1958; Vol. 4, pp 254-894.

(8) Loubière, S.; Laurent, C.; Bonino, J. P.; Rousset, A. Elaboration, Microstructure and Reactivity of Cr3C2 Powders of Different Morphology. Mater. Res. Bull. 1995, 30, 1535-1546.

(9) Berg, G.; Friedrich, C.; Broszeit, E.; Berger, C. Development of Chromium Nitride Coatings Substituting Titanium Nitride. Surf. Coat. Technol. 1996, 86-87, 184-191.

(10) Navinšek, B.; Panjan, P.; Milošev, I. Industrial Applications of CrN (PVD) Coatings, Deposited at High and Low Temperatures. Surf. Coat. Technol. 1997, 97, 182-191.

(11) Mayrhofer, P. H.; Willmann, H.; Mitterer, C. Oxidation Kinetics of Sputtered Cr-N Hard Coatings. Surf. Coat. Technol. 2001, 146-147, 222-228.

(12) Čekada, M.; Panjan, P.; Maček, M.; Šmíd, P. Comparison of Structural and Chemical Properties of Cr-Based Hard Coatings. Surf. Coat. Technol. 2002, 151-152, 31-35.

(13) Kok, Y. N.; Hovsepian, P. E. Resistance of Nanoscale Multilayer C/Cr Coatings against Environmental Attack. Surf. Coat. Technol. 2006, 201, 3596-3605. 
(14) Cheng, F.; Wang, Y.; Yang, T. Microstructure and Wear Properties of Fe-VC-Cr7C3 Composite Coating on Surface of Cast Steel. Mater. Charact. 2008, 59, 488-492.

(15) Vetter, J. Vacuum Arc Coatings for Tools: Potential and Application. Surf. Coat. Technol. 1995, 76-77, 719-724.

(16) Reiter, A. E.; Derflinger, V. H.; Hanselmann, B.; Bachmann, T.; Sartory, B. Investigation of the Properties of Al1-xCrxN Coatings Prepared by Cathodic Arc Evaporation. Surf. Coat. Technol. 2005, 200, 2114-2122.

(17) Post, B.; Glaser, F. W.; Moskowitz, D. Transition Metal Diborides. Acta Metall. 1954, 2, 20-25.

(18) Lundström, T. Transition Metal Borides. In Boron and Refractory Borides; Matkovich, D. V. I., Ed.; Springer Berlin Heidelberg, 1977; pp 351-376.

(19) Samsonov, G. V.; Vinitskii, I. M. In Handbook of Refractory Compounds | Gregory Samsonov | Springer; 1980; p 182.

(20) Knappschneider, A.; Litterscheid, C.; Dzivenko, D.; Kurzman, J. A.; Seshadri, R.; Wagner, N.; Beck, J.; Riedel, R.; Albert, B. Possible Superhardness of CrB4. Inorg. Chem. 2013, 52, 540-542.

(21) Han, L.; Wang, S.; Zhu, J.; Han, S.; Li, W.; Chen, B.; Wang, X.; Yu, X.; Liu, B.; Zhang, R.; et al. Hardness, Elastic, and Electronic Properties of Chromium Monoboride. Appl. Phys. Lett. 2015, 106, 221902.

(22) Zhang, R. F.; Wen, X. D.; Legut, D.; Fu, Z. H.; Veprek, S.; Zurek, E.; Mao, H. K. Crystal Field Splitting Is Limiting the Stability and Strength of Ultra-Incompressible Orthorhombic Transition Metal Tetraborides. Sci. Rep. 2016, 6, 23088.

(23) Okada, S.; Shishido, T.; Yubuta, K.; Mori, T. Synthesis and Some Properties of a New Chromium Boride Cr2B3. Pac. Sci. Rev. 2012, 14, 97-102.

(24) Wang, S.; Yu, X.; Zhang, J.; Zhang, Y.; Wang, L.; Leinenweber, K.; Xu, H.; Popov, D.; Park, C.; Yang, W.; et al. Crystal Structures, Elastic Properties, and Hardness of HighPressure Synthesized CrB2 and CrB4. J. Superhard Mater. 2014, 36, 279-287.

(25) Coltters, R. G.; Belton, G. R. High Temperature Thermodynamic Properties of the Chromium Carbides Cr7C3 and Cr3C2 Determined Using a Galvanic Cell Technique. Metall. Trans. B 15, 517-521.

(26) Xie, J. Y.; Chen, N. X.; Teng, L. D.; Seetharaman, S. Atomistic Study on the Site Preference and Thermodynamic Properties for Cr23-xFexC6. Acta Mater. 2005, 53, 5305-5312.

(27) Inoue, A.; Masumoto, T. Formation of Nonequilibrium $\mathrm{Cr} 3 \mathrm{C}$ Carbide in $\mathrm{Cr} \mathrm{C}$ Binary Alloys Quenched Rapidly from the Melt. Scr. Metall. 1979, 13, 711-715.

(28) Liu, B. X.; Cheng, X. Y. A Metastable Cr Carbide of NaCl Structure Formed by CarbonIon Implantation into Chromium Films. J. Phys. Condens. Matter 1992, 4, L265.

(29) Uebing, C.; Scheuch, V.; Kiskinova, M.; Bonzel, H. P. Segregation of Ordered CrN and CrC Surface Phases on a Fe-15\%Cr(100) Crystal. Surf. Sci. 1994, 321, 89-99.

(30) Andersson, J.-O. A Thermodynamic Evaluation of the Fe-Cr-C System. Metall. Trans. A 1988, 19, 627-636.

(31) Šimůnek, A. How to Estimate Hardness of Crystals on a Pocket Calculator. Phys. Rev. B 2007, 75, 172108.

(32) Li, Y.; Gao, Y.; Xiao, B.; Min, T.; Yang, Y.; Ma, S.; Yi, D. The Electronic, Mechanical Properties and Theoretical Hardness of Chromium Carbides by First-Principles Calculations. J. Alloys Compd. 2011, 509, 5242-5249. 
(33) Jellad, A.; Labdi, S.; Benameur, T. On the Hardness and the Inherent Ductility of Chromium Carbide Nanostructured Coatings Prepared by RF Sputtering. J. Alloys Compd. 2009, 483, 464-467.

(34) Motono, H.; Yoshinaka, M.; Hirota, K.; Yamaguchi, O. Simultaneous Synthesis and Sintering of Chromium Carbide (Cr7C3) Powder by Spark Plasma Sintering Method. $J$. Jpn. Soc. Powder Powder Metall. 2003, 50, 372-376.

(35) Esteve, J.; Romero, J.; Gómez, M.; Lousa, A. Cathodic Chromium Carbide Coatings for Molding Die Applications. Surf. Coat. Technol. 2004, 188-189, 506-510.

(36) Hasegawa, M.; Yagi, T. Systematic Study of Formation and Crystal Structure of 3dTransition Metal Nitrides Synthesized in a Supercritical Nitrogen Fluid under $10 \mathrm{GPa}$ and $1800 \mathrm{~K}$ Using Diamond Anvil Cell and YAG Laser Heating. J. Alloys Compd. 2005, 403, 131-142.

(37) Rivadulla, F.; Bañobre-López, M.; Quintela, C. X.; Piñeiro, A.; Pardo, V.; Baldomir, D.; López-Quintela, M. A.; Rivas, J.; Ramos, C. A.; Salva, H.; et al. Reduction of the Bulk Modulus at High Pressure in CrN. Nat. Mater. 2009, 8, 947-951.

(38) Corliss, L. M.; Elliott, N.; Hastings, J. M. Antiferromagnetic Structure of CrN. Phys. Rev. 1960, 117, 929-935.

(39) Wang, S.; Yu, X.; Zhang, J.; Chen, M.; Zhu, J.; Wang, L.; He, D.; Lin, Z.; Zhang, R.; Leinenweber, K.; et al. Experimental Invalidation of Phase-Transition-Induced Elastic Softening in CrN. Phys. Rev. B 2012, 86, 64111.

(40) Zhang, X. Y.; Chawla, J. S.; Deng, R. P.; Gall, D. Epitaxial Suppression of the MetalInsulator Transition in CrN. Phys. Rev. B 2011, 84, 73101.

(41) Filippetti, A.; Hill, N. A. Magnetic Stress as a Driving Force of Structural Distortions: The Case of CrN. Phys. Rev. Lett. 2000, 85, 5166-5169.

(42) Alling, B.; Marten, T.; Abrikosov, I. A. Questionable Collapse of the Bulk Modulus in CrN. Nat. Mater. 2010, 9, 283-284.

(43) Herwadkar, A.; Lambrecht, W. R. L. Electronic Structure of CrN: A Borderline Mott Insulator. Phys. Rev. B 2009, 79, 35125.

(44) Alling, B.; Marten, T.; Abrikosov, I. A. Effect of Magnetic Disorder and Strong Electron Correlations on the Thermodynamics of CrN. Phys. Rev. B 2010, 82, 184430.

(45) Hones, P.; Sanjines, R.; Levy, F. Characterization of Sputter-Deposited Chromium Nitride Thin Films for Hard Coatings. Surf. Coat. Technol. 1997, 94-95, 398-402.

(46) Tricoteaux, A.; Jouan, P. Y.; Guerin, J. D.; Martinez, J.; Djouadi, A. Fretting Wear Properties of CrN and Cr2N Coatings. Surf. Coat. Technol. 2003, 174-175, 440-443.

(47) Lin, J.; Sproul, W. D.; Moore, J. J.; Lee, S.; Myers, S. High Rate Deposition of Thick $\mathrm{CrN}$ and Cr2N Coatings Using Modulated Pulse Power (MPP) Magnetron Sputtering. Surf. Coat. Technol. 2011, 205, 3226-3234.

(48) Qi, Z. B.; Liu, B.; Wu, Z. T.; Zhu, F. P.; Wang, Z. C.; Wu, C. H. A Comparative Study of the Oxidation Behavior of $\mathrm{Cr} 2 \mathrm{~N}$ and CrN Coatings. Thin Solid Films 2013, 544, 515520.

(49) Aguas, M. D.; Nartowski, A. M.; Parkin, I. P.; MacKenzie, M.; Craven, A. J. Chromium Nitrides (CrN, Cr2N) from Solid State Metathesis Reactions: Effects of Dilution and Nitriding Reagent. J. Mater. Chem. 1998, 8, 1875-1880.

(50) Eriksson, S. 1934, 118, 530-543.

(51) Shah, H. N.; Jayaganthan, R.; Kaur, D.; Chandra, R. Influence of Sputtering Parameters and Nitrogen on the Microstructure of Chromium Nitride Thin Films Deposited on Steel 
Substrate by Direct-Current Reactive Magnetron Sputtering. Thin Solid Films 2010, 518, 5762-5768.

(52) Cecchini, R.; Fabrizi, A.; Cabibbo, M.; Paternoster, C.; Mavrin, B. N.; Denisov, V. N.; Novikova, N. N.; Haïdopoulo, M. Mechanical, Microstructural and Oxidation Properties of Reactively Sputtered Thin CrN Coatings on Steel. Thin Solid Films 2011, 519, 65156521.

(53) Kim, S.-J.; Marquart, T.; Franzen, H. F. Structure Refinement for Cr2N. J. Common Met. 1990, 158, L9-L10.

(54) Yan, M. F.; Chen, H. T. Structural, Elastic and Electronic Properties of Cr2N: A FirstPrinciples Study. Comput. Mater. Sci. 2014, 88, 81-85.

(55) Okada, S.; Kudou, K.; Iizumi, K.; Kudaka, K.; Higashi, I.; Lundström, T. Single-Crystal Growth and Properties of $\mathrm{CrB}, \mathrm{Cr} 3 \mathrm{~B} 4, \mathrm{Cr} 2 \mathrm{~B} 3$ and $\mathrm{CrB} 2$ from High-Temperature Aluminum Solutions. J. Cryst. Growth 1996, 166, 429-435.

(56) Jiang, C. First-Principles Study of Structural, Elastic, and Electronic Properties of Chromium Carbides. Appl. Phys. Lett. 2008, 92, 41909.

(57) Xiao, B.; Xing, J. D.; Feng, J.; Li, Y. F.; Zhou, C. T.; Su, W.; Xie, X. J.; Chen, Y. H. Theoretical Study on the Stability and Mechanical Property of Cr7C3. Phys. B Condens. Matter 2008, 403, 2273-2281.

(58) Yakel, H. L. Atom Distributions in Tau-Carbide Phases: $\mathrm{Fe}$ and $\mathrm{Cr}$ Distributions in $(\mathrm{Cr}$ $\left.{ }_{23-} X \mathrm{Fe}_{X}\right) \mathrm{C}_{6}$ with $X=0,0 \cdot 7_{4}, 1 \cdot 7_{0}, 4 \cdot 1_{3}$ and 7.3 6. Acta Crystallogr. B 1987, 43, $230-238$.

(59) Chen, X.-Q.; Niu, H.; Li, D.; Li, Y. Modeling Hardness of Polycrystalline Materials and Bulk Metallic Glasses. Intermetallics 2011, 19, 1275-1281.

(60) Fahy, S.; Louie, S. G.; Cohen, M. L. Pseudopotential Total-Energy Study of the Transition from Rhombohedral Graphite to Diamond. Phys Rev B 1986, 34, 1191-1199.

(61) Furthmüller, J.; Hafner, J.; Kresse, G. Ab Initio Calculation of the Structural and Electronic Properties of Carbon and Boron Nitride Using Ultrasoft Pseudopotentials. Phys Rev B 1994, 50, 15606-15622.

(62) J Haines; JM Léger; Bocquillon, G. Synthesis and Design of Superhard Materials. Annu. Rev. Mater. Res. 2001, 31, 1-23.

(63) Hirota, K.; Mitani, K.; Yoshinaka, M.; Yamaguchi, O. Simultaneous Synthesis and Consolidation of Chromium Carbides (Cr3C2, Cr7C3 and Cr23C6) by Pulsed ElectricCurrent Pressure Sintering. Mater. Sci. Eng. A 2005, 399, 154-160.

(64) Xiao, B.; Feng, J.; Zhou, C. T.; Xing, J. D.; Xie, X. J.; Chen, Y. H. First Principles Study on the Electronic Structures and Stability of Cr7C3 Type Multi-Component Carbides. Chem. Phys. Lett. 2008, 459, 129-132.

(65) Yu, H.; Duan, D.; Tian, F.; Liu, H.; Li, D.; Huang, X.; Liu, Y.; Liu, B.; Cui, T. Polymerization of Nitrogen in Ammonium Azide at High Pressures. J. Phys. Chem. C 2015, 119, 25268-25272.

(66) Popov, M. Raman and IR Study of High-Pressure Atomic Phase of Nitrogen. Phys. Lett. A 2005, 334, 317-325.

(67) Müller, U. Inorganic Structural Chemistry; John Wiley \& Sons, 2007.

(68) Stishov, S. M.; Popova S.V. A New Dense Modification of Silica. Geochem 1961, 10, 923-926. 
(69) Novoselov, K. S.; Jiang, D.; Schedin, F.; Booth, T. J.; Khotkevich, V. V.; Morozov, S. V.; Geim, A. K. Two-Dimensional Atomic Crystals. Proc Natl Acad Sci 2005, 102, 10451-10453.

(70) Clark, K. W.; Qin, S.; Zhang, X.-G.; Li, A.-P. Nanoscale Periodic Modulations on Sodium Chloride Surface Revealed by Tuning Fork Atomic Force Microscopy. Nanotechnology 2012, 23, 185306.

(71) Qian, G.-R.; Dong, X.; Zhou, X.-F.; Tian, Y.; Oganov, A. R.; Wang, H.-T. Variable Cell Nudged Elastic Band Method for Studying Solid-solid Structural Phase Transitions. Comput. Phys. Commun. 2013, 184, 2111-2118.

(72) Kinney, G. F.; Graham, K. J. Explosive Shocks in Air; Springer Science \& Business Media: New York, 1985.

(73) O'Neil, M. J. The Merck Index - An Encyclopedia of Chemicals, Drugs, and Biologicals; Whitehouse Station, NJ: Merck and Co., Inc., 2001.

(74) Asay, B. Shock Wave Science and Technology Reference Library, Vol. 5, 1st ed.; Springer-Verlag Berlin Heidelberg, 2010.

(75) Oganov, A. R.; Glass, C. W. Crystal Structure Prediction Using Ab Initio Evolutionary Techniques: Principles and Applications. J Chem Phys 2006, 124, 244704.

(76) Oganov, A. R.; Glass, C. W. Evolutionary Crystal Structure Prediction as a Method for the Discovery of Minerals and Materials. Rev Miner. Geochem 2010, 271.

(77) Oganov, A. R.; Lyakhov, A. O.; Valle, M. How Evolutionary Crystal Structure Prediction Works - and Why. Acc. Chem. Res. 2011, 44, 227-237.

(78) Lyakhov, A. O.; Oganov, A. R.; Valle, M. How to Predict Very Large and Complex Crystal Structures. Comput. Phys. Commun. 2010, 181, 1623-1632.

(79) Lyakhov, A. O.; Oganov, A. R.; Stokes, H. T.; Zhu, Q. New Developments in Evolutionary Structure Prediction Algorithm USPEX. Comput. Phys. Commun. 2013, 184, 1172-1182.

(80) Glass, C. W.; Oganov, A. R.; Hansen, N. USPEX-Evolutionary Crystal Structure Prediction. Comput. Phys. Commun. 2006, 175, 713-720.

(81) Hohenberg, P.; Kohn, W. Inhomogeneous Electron Gas. Phys Rev 1964, 136 (3B), B864-B871.

(82) Kohn, W.; Sham, L. J. Self-Consistent Equations Including Exchange and Correlation Effects. Phys Rev 1965, 140 (4), A1133-A1138.

(83) Perdew, J. P.; Burke, K.; Ernzerhof, M. Generalized Gradient Approximation Made Simple. Phys. Rev. Lett. 1996, 77 (18), 3865-3868.

(84) Kresse, G.; Hafner, J. Ab Initio Molecular Dynamics for Liquid Metals. Phys. Rev. B 1993, 47 (1), 558-561.

(85) Kresse, G.; Hafner, J. Ab Initio Molecular-Dynamics Simulation of the Liquid-MetalAmorphous-Semiconductor Transition in Germanium. Phys. Rev. B 1994, 49 (20), 14251-14269.

(86) Kresse, G.; Furthmüller, J. Efficient Iterative Schemes for Ab Initio Total-Energy Calculations Using a Plane-Wave Basis Set. Phys. Rev. B 1996, 54 (16), 11169-11186.

(87) Anisimov, V. I.; Zaanen, J.; Andersen, O. K. Band Theory and Mott Insulators: Hubbard U instead of Stoner I. Phys. Rev. B 1991, 44, 943-954.

(88) Dudarev, S. L.; Botton, G. A.; Savrasov, S. Y.; Humphreys, C. J.; Sutton, A. P. ElectronEnergy-Loss Spectra and the Structural Stability of Nickel Oxide: An LSDA+U Study. Phys. Rev. B 1998, 57, 1505-1509. 
(89) Monkhorst, H. J.; Pack, J. D. Special Points for Brillouin-Zone Integrations. Phys. Rev. $B$ 1976, 13 (12), 5188-5192.

(90) Gao, F.; He, J.; Wu, E.; Liu, S.; Yu, D.; Li, D.; Zhang, S.; Tian, Y. Hardness of Covalent Crystals. Phys Rev Lett 2003, 91, 015502-015506.

(91) Kern, G.; Kresse, G.; Hafner, J. Ab Initio Calculation of the Lattice Dynamics and Phase Diagram of Boron Nitride. Phys Rev B 1999, 59, 8551-8559.

(92) Togo, A.; Tanaka, I. First Principles Phonon Calculations in Materials Science. Scr. Mater. 2015, 108, 1-5.

(93) Togo, A.; Oba, F.; Tanaka, I. First-Principles Calculations of the Ferroelastic Transition between Rutile-Type and CaCl2-Type SiO2 at High Pressures. Phys. Rev. B 2008, 78, 134106.

(94) Luo, W.; Windl, W. First Principles Study of the Structure and Stability of Carbynes. Carbon 2009, 47, 367-383.

(95) Kvashnin, A. G.; Chernozatonskii, L. A.; Yakobson, B. I.; Sorokin, P. B. Phase Diagram of Quasi-Two-Dimensional Carbon, From Graphene to Diamond. Nano Lett 2014, 14, 676-681.

(96) Kvashnin, A. G.; Sorokin, P. B. Lonsdaleite Films with Nanometer Thickness. J Phys Chem Lett 2014, 5, 541-548.

(97) Oganov, A. R.; Gillan, M. J.; Price, G. D. Ab Initio Lattice Dynamics and Structural Stability of MgO. J Chem Phys 2003, 118, 10174-10182.

(98) Oganov, A. R.; Gillan, M. J.; Price, G. D. Structural Stability of Silica at High Pressures and Temperatures. Phys. Rev. B 2005, 71, 64104.

(99) Oganov, A. R.; Ono, S. Theoretical and Experimental Evidence for a Post-Perovskite Phase of MgSiO3 in Earth's D' Layer. Nature 2004, 430, 445-448.

(100) Momma, K.; Izumi, F. VESTA 3 for Three-Dimensional Visualization of Crystal, Volumetric and Morphology Data. J. Appl. Crystallogr. 2011, 44, 1272-1276. 